\title{
Three dimensional reconstruction of the left ventricle from multiple cross sectional echocardiograms Value for measuring left ventricular volume
}

\author{
HITOSHI SAWADA, JUNICHI FUJII, KAZUZO KATO, MORIO ONOE, YOSHINORI KUNO \\ From the Cardiovascular Institute, Minato-Ku, Tokyo, and the Institute of Industrial Science, University of Tokyo, \\ Tokyo
}

SUMMARY The accuracy of a system for reconstructing a three dimensional image of the left ventricle from randomly recorded multiple short axis images was tested by comparing the calculated left ventricular volume with the directly measured left ventricular volume in 11 excised porcine hearts. The system comprised a real time phased array sector scanner, a transducer locating system, and a computer system for digitising outlines of the left ventricle, displaying the reconstruction image, and calculating the left ventricular volume. The reconstructed image was similar to the real image and the calculated left ventricular volume showed a high correlation with the directly measured left ventricular volume.

This method was accurate in vitro and is expected to be available for clinical measurement of left ventricular volume.

Measurement of left ventricular volume is important in the quantitative assessment of left ventricular function. Although there have been some attempts at measuring left ventricular volume by cross sectional echocardiography, ${ }^{1-11}$ three dimensional reconstruction of the left ventricular images could provide a more accurate spatial image of the heart, thus providing a more accurate assessment of left ventricular volume; a few attempts have been reported recently. ${ }^{12-17}$ Short axis cross sectional echocardiographic imaging of the left ventricle is easy to perform non-invasively and shows an extensive sectional image of the left ventricle around its entire circumference at multiple sectional levels. If the spatial positions of multiple short axis images from the base to the apex are known, three dimensional coordinates of any portion of the left ventricle can be determined.

The accuracy of a system to reconstruct a three dimensional image of the left ventricle from randomly recorded multiple short axis images was tested by comparing calculated left ventricular volume with directly measured left ventricular volume in 11 excised porcine hearts.

Accepted for publication 7 July 1983

\section{Methods}

\section{(1) INSTRUMENTS}

The system comprises a real time phased array sector scanner, a transducer locating system, and a computer system for digitising outlines of the left ventricle, displaying the reconstruction images, and calculating the left ventricular volume. The transducer locating system was developed to record the cross sectional echocardiogram and determine the spatial coordinates (Fig. 1 and 2). The probe was attached to a special arm with three movable joints, and movement of the probe had to be in a plane nearly parallel to the long axis of left ventricle. Changes in the angle of the arm were converted into changes in voltage by potentiometers. Rotation of the transducer was measured visually. Changes of the voltage in the potentiometers were displayed and printed out on the digital panel printer (Asahi Keiki).

Short axis cross sectional images of the left ventricle were recorded on video tape using a phased array sector scanner (Aloka SSD-800). Outlines of the left ventricle were traced manually with a video motion analyser (Sonny SMV-1100) and then digitised and stored in the computer. Each digitised image consisted of $256 \times 256$ pixels with a grey level of $256 \mathrm{~Gy}$. 


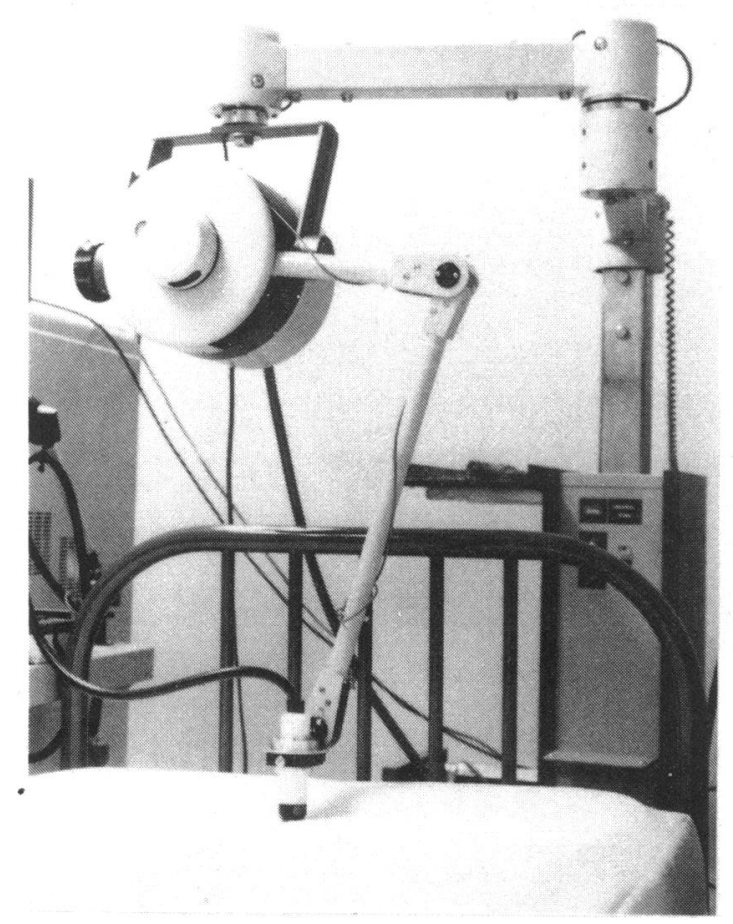

Fig. 1 Transducer locating system. The probe of the phased array sector scanner is attached to the special arm with three movable joints and potentiometers.

(2) DETERMINATION OF THE SPATIAL POSITION The spatial position of the cross sectional short axis image was determined by the voltage output of the potentiometers in the transducer locating system on the assumption that the patient did not move while

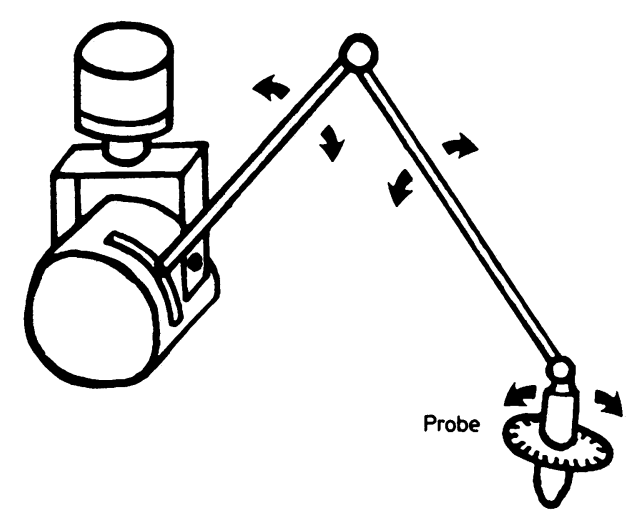

Fig. 2 Arrangement of the special arm with three movable joints.

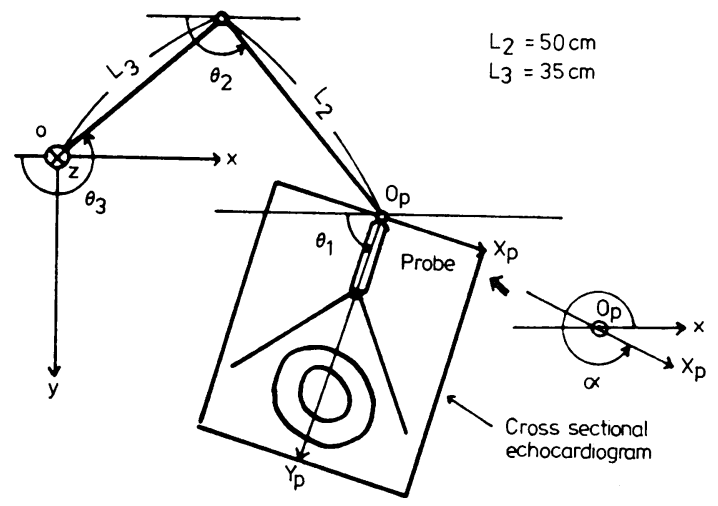

$$
\begin{aligned}
x= & X_{p} \cos \propto \sin \theta_{1}-Y_{p} \cos \theta_{1} \\
& -L_{2} \cos \theta_{2}-L_{3} \cos \theta_{3} \\
y= & X_{p} \cos \propto \cos \theta_{1}+Y_{p} \sin \theta_{1} \\
& +L_{2} \sin \theta_{2}+L_{3} \sin \theta_{3} \\
z= & X_{p} \sin \alpha
\end{aligned}
$$

Fig. 3 Determination of the spatial position. Xp,Yp: two dimensional coordinates of the short axis images; $X, Y, Z$ : three dimensional coordinates.

recording. Two dimensional coordinates of the short axis images $(\mathrm{Xp}, \mathrm{Yp})$ were determined as follows. A line which bisected the sector at the origin of the beam was named the $\mathrm{Y}$ axis, the point where the probe was connected to the arm system was named $\mathrm{Op}$, and a line which perpendicularly intersected the $\mathrm{Y}$ axis at the point $\mathrm{Op}$ was named the $\mathrm{X}$ axis. The length was corrected using the scale markers, and the two dimensional coordinates $(\mathrm{Xp}, \mathrm{Yp})$ of the images were determined. The next step was to determine three dimensional coordinates. The point where the arm was connected to the main part of the recording system was named point $\mathrm{O}$. A horizontal line perpendicular to the arm was named the $Z$ axis, another horizontal line the $\mathrm{X}$ axis, and a vertical line the $\mathrm{Y}$ axis. With this system two dimensional coordinates $(\mathrm{Xp}, \mathrm{Yp}$ ) were converted into three dimensional coordinates $(X, Y, Z)$ by the formulas shown in Fig. 3.

\section{(3) RECONSTRUCTION OF THE THREE}

\section{DIMENSIONAL IMAGE OF THE LEFT VENTRICLE}

Three dimensional reconstruction of the left ventricle was performed by a realignment of about 10 short axis images using a software of Movie Byu developed by Christiansen and Stephenson. ${ }^{18}$ The principle of this program is to cover the spaces between the outlines of two short axis images with squares or triangles (Fig. 6). This program has many functions such as elimination of hidden surfaces, shading, rotation of the three dimensional image, and division of the reconstructed image. 


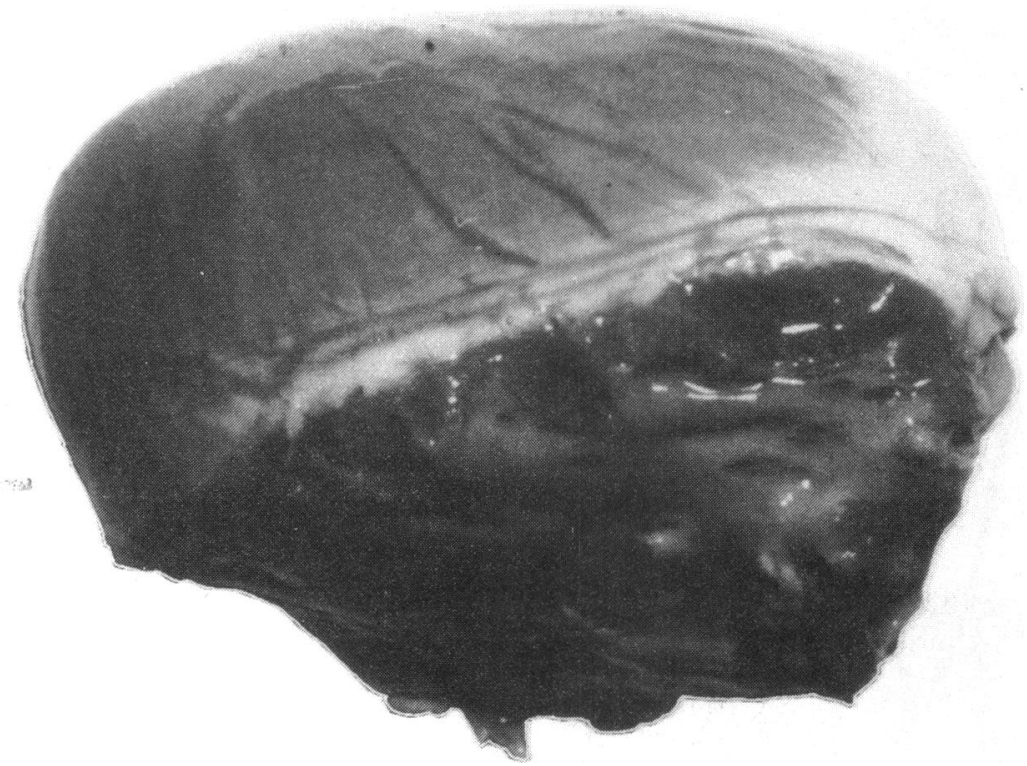

Fig. 4 Excised porcine heart prepared by removing the atria, valve leaflets, aorta, pulmonary artery, and right ventricle.

\section{(4) CALCULATION OF LEFT VENTRICULAR VOLUME}

A line which connected the centre of gravity of the most apical and basal short axis images was used as a standard line. Each of the reconstructed images of the left ventricle was divided into 50 slices by 50 parallel planes perpendicular to this line at equal intervals. Left ventricular volume was calculated simply by summation of the volumes of 50 slices of the left ventricle.

\section{(5) EXPERIMENT}

Eleven porcine hearts were excised, and the base of the left ventricle of each heart was identified by removing the atria, valve leaflets, aorta, pulmonary artery, and right ventricle (Fig. 4). Each heart was placed in a water bath filled with isotonic saline of $37^{\circ} \mathrm{C}$. About 10 short axis cross sectional echocardiograms were recorded from the base to the apex at intervals of about $1 \mathrm{~cm}$. Figure 5 shows one of those images. The outlines of these recorded images were traced, digitised, and stored in the computer. The volume of the left ventricle was then measured directly from the mass of water that it displaced.

Direct measurement of left ventricular volume and calculation of left ventricular volume from the three dimensional reconstructed image was performed three times for each heart, and mean values were taken. The results were tested by analysis of variance.

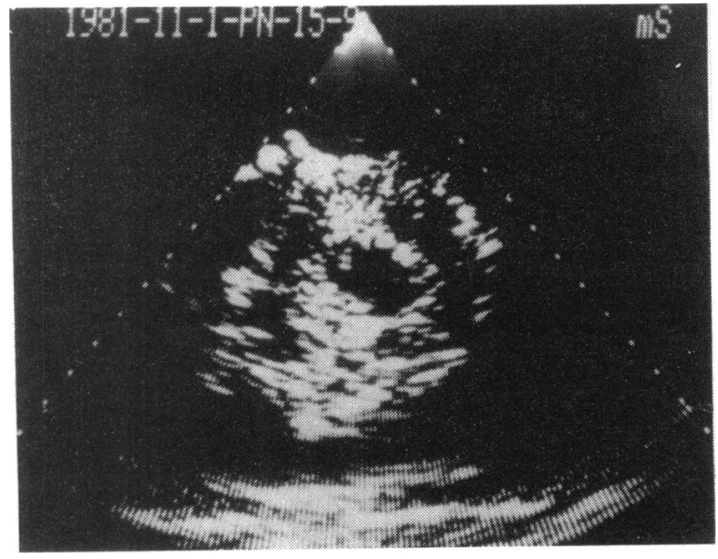

Fig. 5 Example of a short axis cross sectional echocardiogram of an excised porcine heart.

\section{Results}

Reconstructed images of the left ventricles closely 2 resembled excised porcine hearts (Fig. 4 and 6). The mean values ( \pm SD) directly measured and calculated left ventricular volumes of the 11 samples were $230.4 \pm 30.9 \mathrm{ml}$ and $234.4 \pm 29.3 \mathrm{ml}$, respectively. By linear regression a high correlation was found between directly measured and calculated left ventricular volumes $(r=0.928, p<0.001, S E E=11.6)$ (Fig. 7). Two 


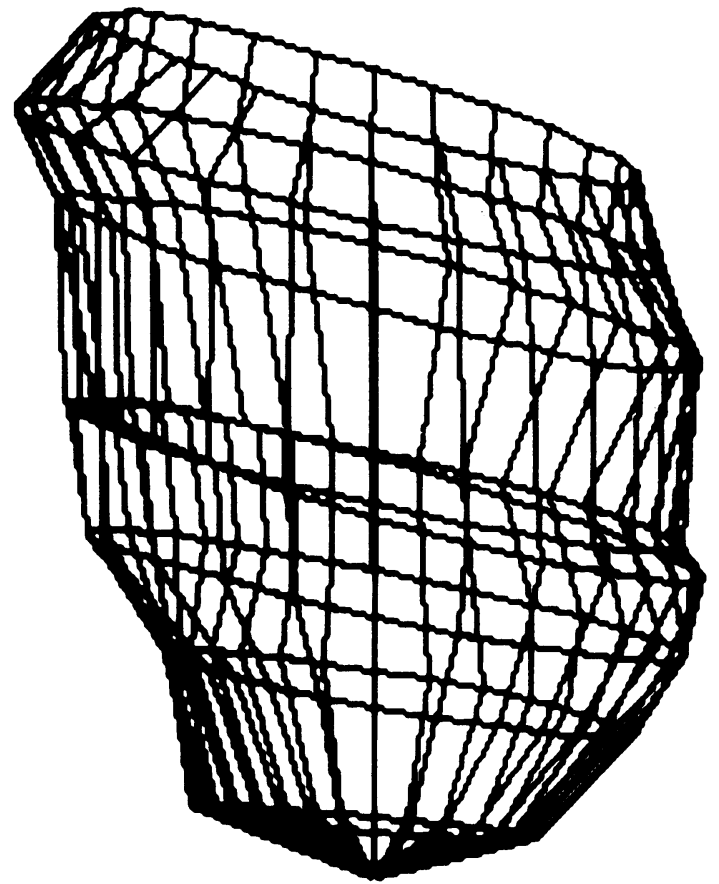

Fig. 6 Reconstructed image of the left ventricle of the heart shown in Fig. 4.

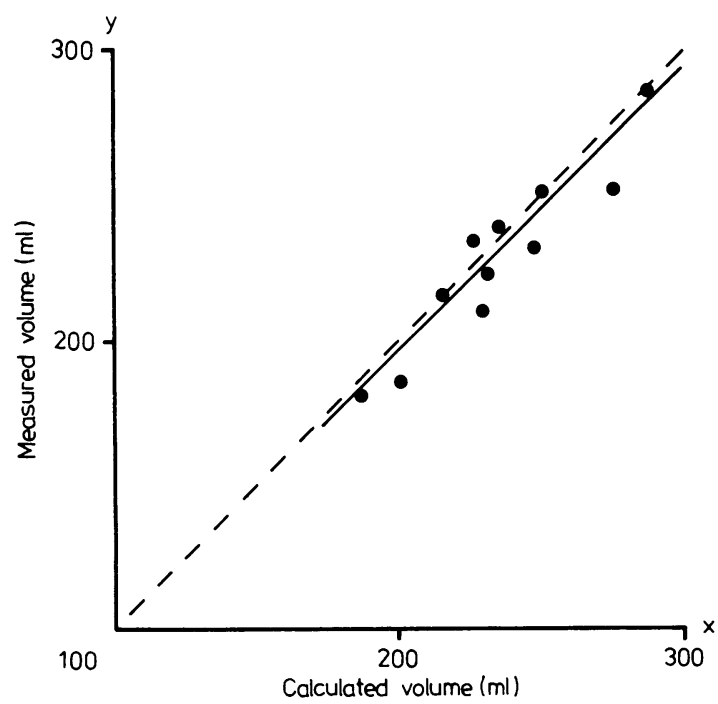

Fig. 7 Correlation between calculated left ventricular volume and directly measured left ventricular volume in 11 excised porcine hearts. $(y=0.98 x+0.76 ; S E E=11 \cdot 6 ; r=0.93$; $p<0.001 ; n=11$.) way analysis of variance showed that there were no significant differences between measured values by both methods $(\mathrm{F}=1 \cdot 39)$.

The reproducibility of the direct measurements and calculations was assessed by calculating for each heart the difference between the maximum and minimum measurements divided by the mean of the three measurements. The mean and standard deviation of these values were $0.035 \pm 0.008$ (range $0.032-0.047$ ) for direct measurements and $0.066 \pm 0.028$ (range 0.0310.119) for calculations.

\section{Discussion}

This system is non-invasive, the reconstructed image is similar to the real image, and the calculated volume was accurate in vitro.

There are some possible sources of error with this method. The first one is the reliability of the registration system, including the accuracy and variability of tilt and rotation of the arm. A preliminary test showed that these were satisfactory. The second possible error originates from recording the basal portion of the left ventricle and apex. The base of the left ventricle was deformed and a complicated shape, and it was sometimes difficult to obtain a complete image. The volume of this portion, however, was at most $10 \mathrm{ml}$. The method of Geiser $e t$ al. ${ }^{1516}$ used an apical or parasternal long axis view to determine the apex, but it is often difficult to determine the position of the true apex from an apical or parasternal long axis view. In our system the apex was determined from multiple short axis images of the apical portion recorded by angulating and changing the position of the transducer. It is still difficult, however, to record the entire image of the anatomical fibrous apex of the heart. The third anticipated source of error is introduced by the resolution of a phased array sector scanner and difficulty in defining the endocardial and epicardial border of the short axis image.

Despite these anticipated sources of error the calculated volume resulted in relatively small deviations from true values. Moreover, measuring left ventricular volume by this system does not require any assumption of a prolate or ellipsoidal model. Digitised data are easy to process by a computer and much information such as volume, shape, distribution of myocardial hypertrophy, and wall motion can be obtained.

Some points could be improved. Firstly, outlines were traced manually in this study. Automatic edge detection of the left ventricular wall could be performed by an algorithm using a combination of a threshold and second derivative technique and spline fitting technique as shown in our previous study. ${ }^{19}$ This computer technique, of course, could be avail- 
able in this three dimensional reconstruction system. Secondly, the arm system has only four degrees of freedom, which is not sufficient to record clear short axis images of the whole left ventricle in adult patients. Thirdly, the reconstruction system is not connected directly to the computer. Development of an interface to transfer information directly to the computer system would be desirable for clinical use.

All of these problems should be solved for a clinical application of this system, which will be possible by systems which have already been developed.

\section{References}

1 Carr KW, Engler RL, Forsythe JR, Johnson AD, Gosink B. Measurement of left ventricular ejection fraction by mechanical cross-sectional echocardiography. Circulation 1979; 59: 1196-206.

2 Eaton LW, Maughan WL, Shoukas AA, Weiss JL. Accurate volume determination in isolated ejecting canine left ventricle by two-dimensional echocardiography. Circulation 1979; 60: 320-6.

3 Schiller NB, Acquatella H, Ports TA, et al. Left ventricular volume from paired biplane two-dimensional echocardiography. Circulation 1979; 60: 547-55.

4 Folland ED, Parisi AF, Moynihan PF, Jones DR, Feldman CL, Tow DE. Assessment of left ventricular ejection fraction and volumes by real-time, two-dimensional echocardiography. A comparison of cineangiographic and radionuclide techniques. Circulation 1979; 60: 7606.

5 Wyatt HL, Heng MK, Meerbaum S, et al. Crosssectional echocardiography I. Analysis of mathematic models for quantifying mass of the left ventricle in dogs. Circulation 1979; 60: 1104-13.

6 Gueret P, Meerbaum S, Wyatt HL, Uchiyama T, Lang TW, Corday E. Two-dimensional echocardiographic quantitation of left ventricular volumes and ejection fraction: importance of accounting for dyssynergy in shortaxis reconstruction models. Circulation 1980; 62: 130818.

7 Wyatt HL, Meerbaum S, Heng MK, Gueret P, Corday E. Cross-sectional echocardiography III. Analysis of mathematic models for quantifying volume of symmetric and asymmetric left ventricles. Am Heart f 1980; 100: 821-8.

8 Helak JW, Reichek N. Quantitation of human left ventricular mass and volume by two-dimensional echocardiography; in vitro anatomic validation. Circulation 1981; 63: 1398-407.
9 Schapira JN, Kohn MS, Beaver WL, Popp RL. In vitro quantification of canine left ventricular volume by phased-array sector scan. Cardiology 1981; 67: 1-11.

10 Mercier JC, DiSessa TG, Jarmakani JM, et al. Twodimensional echocardiographic assessment of left ventricular volumes and ejection fraction in children. Circulation 1982; 65: 962-9.

11 Stamm RB, Carabello BA, Mayers DL, Martin RP. Two-dimensional echocardiographic measurement of left ventricular ejection fraction: prospective analysis of what constitutes an adequate determination. Am Heart $\mathcal{f} 1982$; 104: 136-44.

12 Dekker DL, Piziali RL, Dong E Jr. A system for ultrasonically imaging the human heart in three dimensions. Comput Biomed Res 1974; 7: 544-53.

13 King DL, Al-Banna S, Larach DR. A new threedimensional random scanner for ultrasonic/computer graphic imaging of the heart. In: White $D$, Barnes $R$, eds. Ultrasound in medicine. vol 2. New York: Plenum, 1975: 363.

14 Matsumoto M, Matsuo H, Kitabatake A, et al. Threedimensional echocardiograms and two-dimensional echocardiographic images at desired planes by a computerized system. Ultrasound Med Biol 1977; 3: 163-78.

15 Geiser EA, Lupkiewicz SM, Christie LG, Ariet M, Conetta DA, Conti CR. A framework for 3-dimensional time varying reconstruction of the human left ventricle; sources of error and estimation of their magnitude. Comput Biomed Res 1980; 13: 225-41.

16 Geiser EA, Christie LG, Conetta DA, Conti CR, Gossman GS. A mechanical arm for spatial registration of two-dimensional echocardiographic sections. Cathet Cardiovasc Diagn 1982; 8: 89-101.

17 Tamura S, Matsumoto M, Tanaka K. Volume measurement based on serial ultrasound tomograms. Comput Biol Med 1981; 11: 141-52.

18 Christiansen H, Stephenson M. Interactive computer graphics MOVIE. BYU. Seminar Lecture Note, 1980.

19 Fujii J, Kuboki M, Aizawa T, et al. Digital image processing of the two dimensional echocardiogram for the evaluation of regional contractility of the left ventricular wall [in Japanese with English abstract]. $\mathcal{F}$ Cardiogr 1981; 11: 901-9.

Requests for reprints to Dr Junichi Fujii, Cardiovascular Institute, 7-3-10 Roppongi, Minato-Ku, Tokyo 106, Japan. 